\title{
RESEÑA: LOS PRINCIPIOS DEL GOBIERNO REPRESENTATIVO
}

\section{Edimer Leonardo Latorre Iglesias*}

El trabajo Clásico "Los principios del gobierno representativo" de Bernard Manin lo podemos ubicar en la historia de las ideas políticas, la sociología política y la filosofía política, particularmente impresiona el rigor de los datos históricos, su preocupación por el manejo conceptual y los comentarios originales que elabora de los filósofos clásicos liberales como Hobbes, Rousseau, Montesquieu, Harrington y los clásicos padres fundadores del Republicanismo (proceso que él mismo denomina "escrutinio genealógico" (Manin, 1999)

Manin aporta al desarrollo de la teoría política y por ende de la ciencia política, nuevas herramientas conceptuales que hoy se consideran clásicas, dada la forma como aborda elementos que se consideraban como supuestos fundacionales dentro de la teoría política, poniendo en duda usos del sentido común, mediante la investigación científica y la propuesta de nuevas lecturas de antiguas realidades, como es el caso del sorteo en la elección de los cargos públicos en la Grecia Clásica, demostrando en su estudio, el poder democrático inherente a este sistema, hoy en día en desuso.

Bernard Manin, forma parte de un nutrido grupo de intelectuales que desde posiciones y paradigmas diferentes vienen generando un debate académico sobre el liberalismo, el republicanismo, los gobiernos representativos y la mal denominada crisis de los sistemas políticos o crisis de la representatividad (que no es más que una metamorfosis en palabras de Manin). Igualmente su obra es una crítica a la no democracia que habita en la democracia, siendo esta una paradoja, tal como él lo percibe.

En la obra de Manin se encuentra una visión del gobierno representativo y de las ideas liberales como un instrumento efectivo para refundar la política y el papel activo del ciudadano en los sistemas representativos. La obra de Manin contrapone los sistemas representativos con la idea de la democracia, dejando una gran cantidad de opciones abiertas para que la democracia sea más democrática.

La obra inicia con el análisis de la figura del sorteo en la democracia griega y finaliza la misma con las metamorfosis de los sistemas representativos en el mundo moderno. Los cuatro primeros capítulos del texto están dirigidos a precisar cómo se van desarrollando los principios del gobierno representativo, pero de igual forma muestran la evolución de la idea política de la representatividad. Precisa como pasamos de una distribución igualitaria del poder entre los ciudadanos (el sorteo en la democracia griega, primera idea de representatividad), luego como esta idea va dando forma a una nueva concepción, el consentimiento del poder por parte de los ciudadanos (proceso que se da sobre todo en el feudalismo y se concreta con las revoluciones políticas del siglo XVIII), y finalmente termina con

* Candidato a Doctor en Sociología Jurídica e instituciones políticas de la Universidad Externado de Colombia. Es director del grupo de investigación comunicación y sociedad de la Escuela de Comunicación de la Universidad Sergio Arboleda Seccional Santa Marta. Correo electrónico: edimerlatorre@hotmail.com 
la tercera idea que es la distinción del poder por parte de los ciudadanos, concepción totalmente aristocrática, la cual se materializa en los sistemas representativos modernos.

Para mostrarnos estas ideas, recurre al árbol genealógico de todos los teóricos clásicos, que le dan vida a la concepción de la representatividad: Aristóteles y su constitución mixta, Harrington y la Oceanía, Montesquieu y su espíritu de las leyes, Rousseau y su crítica a la representatividad, Madison y los Federalistas.

Interesa, que aborda de igual forma a aquellos que eran críticos del sistema representativo y los contextualiza en el momento histórico en el cual fundamentaron sus ideas, así como en el entorno social y cultural donde se dieron los cambios en el sistema representativo. El capitulo 5, se caracteriza por el desarrollo conceptual de los cuatro principios clásicos de los gobiernos representativos, los cuales podemos resumir:

1. La independencia parcial de los representantes: este principio enmarca la necesidad de cumplir las promesas del electorado, y demuestra como en el fondo el veredicto del pueblo puede ser un elemento vinculante con las decisiones que tomen los representantes, pero en el fondo no existe ningún poder que obligue a los elegidos a cumplir con las promesas electorales.

2. La libertad de opinión pública: el supuesto básico desde los teóricos de la representación es que la libertad de opinión sopesaría la ausencia de promesas vinculantes, dándole a los electores la posibilidad de crear corrientes de opiniones públicas que incidieran en las decisiones de los representantes. La realidad como lo demuestra Manin, es que la opinión pública queda en manos de los que hacen la opinión, es decir, de los que hacen los sondeos de opiniones que guían tendenciosamente la agenda pública y la agenda política (Elster, 1998), lo que en ultimas genera unos sistemas basados en la lógica y los resultados de encuestas, haciendo que la política gire en los problemas de la inmediatez.
3. El carácter periódico de las elecciones: supuestamente las elecciones y la periodicidad de las mismas permitirán que los electores regulen las acciones políticas de sus representantes. Lo que demuestra Manin, es que los votantes tienen en cuenta el pasado a la hora de tomar decisiones y no el presente.

4. Juicio mediante la discusión: otro de los supuestos clásicos es que la toma de decisiones en los sistemas representativos se basa en la verdad consensuada y en el convencimiento racional de los miembros. La verdad aparecerá mediante el uso de la razón que surge en medio del proceso de discusión. En su estudio Manin diferencia regateo, discusión, deliberación y debate, precisando sobre todo los límites y las bondades de cada uno de estos procesos, para afirmar que: "El gobierno representativo no es un sistema en el que todo se tenga que originar en el debate, sino aquél en el que todo ha de justificarse en el debate" (Elster, 1998, p. 234).

Finalmente Manin termina su obra con una explicación de la crisis de la representatividad en los sistemas políticos modernos, demostrando ha evolucionado de un sistema parlamentario, pasando por una democracia de partidos y finalizando con el concepto, que a mi juicio más validez posee en la actualidad, el de democracia de audiencias, donde Manin, demuestra como la politica de la representatividad queda en el poder de los medios, los cuales mediante estrategias de marketing de opinión, logran entrar en el mercado de la oferta electoral, buscando una respuesta de las audiencias.

En las conclusiones del texto Los principios del gobierno representativo, el autor expone un detallado resumen de la obra en general, dejando clara la idea de cómo los gobiernos representativos fueron fundados como opuestos a la democracia y hoy se consideran una forma de la misma. Así mismo, señala como el voto popular permite creer en la falacia de un gobierno popular, pero considera que la representación es hoy mas 
que nunca un gobierno aristocrático y de elites (aunque cada grupo históricamente determina que es una elite, o que hay que destacar de sus representantes).

Termina el texto con el pensamiento Aristotélico de una constitución mixta, donde exista un gobierno democrático pero al mismo tiempo oligárquico, sin dejar de ver ninguno de estos.

Reconforta en la lectura de Manin, el hecho de que en los sistemas representativos a pesar de su dualidad, sigue siendo vital el veredicto del pueblo. Los Colombianos en el momento coyuntural de nuestro acontecer político deberíamos prestar atención a esta lección.

\section{BIBLIOGRAFÍA}

Dahl, R. (1993). La Democracia y sus críticos. Barcelona: Paidos.

Elster, J. (1998). La democracia deliberativa. Barcelona: Gedisa.

Manin, B. (Mayo de 2001 ). ¿Una República con dos regímenes? Post-Data- Revista de reflexión y Análisis Político. , 35-52.

Manin, B. (1999). Los Principios del gobierno representativo. Madrid: Alianza.

Manin, B. (2001). Montesquieau, la república y el comercio (Vol. 8). 